\title{
CULTIVO DO BEM VIVER DAS PESSOAS IDOSAS E TECNOLOGIA CUIDATIVO-EDUCACIONAL DE ENFERMAGEM
}

Thais Monteiro Goes ${ }^{1}$, Sandra Helena Isse Polaro², Lucia Hisako Takase Gonçalves ${ }^{3}$

Objetivo: realizar avaliação diagnóstica de condições de vida e saúde dos idosos convivendo em família e comunidade, usuários de uma Unidade Básica de Saúde - UBS e testar o desenvolvimento de uma tecnologia cuidativo-educacional. Metodologia: pesquisa convergente-assistencial, adotando a técnica do grupo de convergência com 13 idosos, que se desenvolveu em sete encontros, em 2013. Resultados: o estudorevelou perspectivas à enfermeira serfacilitadora no desenvolvimento decompetências ao autocuidado e estimuladora de idosos para que sejam protagonistas do próprio envelhecimento, instrumentalizada por diretrizes da tecnologia leve de atos de cuidado, fundamentada em referências de enfermagem. Conclusão: o estudo apresentou resultados benéficos aos idosos que se submeteram à experiência e também à enfermagem, pela possibilidade de empreender ações cuidativo-educacionais inovadas.

Descritores: Idoso; Tecnologia educacional; Atenção básica; Envelhecimento ativo; Enfermeiro.

\section{GROWING THE ELDERLY'S GOOD LIVING AND CARING-EDUCATIONAL TECHNOLOGIES OF NURSING}

Objective: perform a diagnostic evaluation of living conditions and health of the elderly living in family and community, and users of a Basic Health Unit - UBS, and also test the development of a care-educational technology. Methodology: convergentcare research that adopted the convergence group technique with 13 seniors, which developed during seven meetings in 2013. Results: the paper revealed prospects for the nurse to be a facilitator in the development of self-care skills and stimulate the elderly so that they can be the protagonists of their aging. It was instrumentalized by guidelines of light technology about caring acts based on nursing references. Conclusion: the study presented beneficial results to the elderly who underwent the experience, and also for the nurses, by the possibility of taking innovated caring-educational actions.

Descriptors: Elderly; Educational technology; Primary care; Active aging; Nurse.

\section{CULTIVO DEL BIENVIVIR DE LOS ANCIANOS YTECNOLOGİA CUIDADORA-EDUCACIONAL DE LA ENFERMERİA}

Objetivo: realizar una evaluación diagnóstica de las condiciones de vida y salud de los ancianos que conviven en familia, comunidad y son usuarios de una Unidad Básica de Salud - UBS, y testear el desarrollo de una tecnología cuidadora-educacional. Metodología: investigación convergente-asistencial adoptando la técnica del grupo de convergencia perspectivas para que la enfermera sea facilitadora en el desarrollo de competencias para el autocuidado con 13 ancianos, que se desarrolló durante siete encuentros, en el 2013. Resultados: el estudio rebeló y estimuladora de ancianos para que sean protagonistas del propio envejecimiento; instrumentalizada por directrices de la tecnología leve de actos de cuidado y fundamentada en las referencias de enfermería. Conclusion: el estudio presentó resultados benéficos para los ancianos que se sometieron a la experiencia, y también, para la enfermería, por la posibilidad de emprender acciones cuidadoras-educacionales innovadas.

Descriptores: Anciano; Tecnologia educacional; Atencion primaria, Envejecimiento activo, Enfermero.

1Enfermeira. Mestre em enfermagem. Docente de enfermagem do Instituto Federal de Educação, Ciência e Tecnologia do Pará- IFPA.

${ }^{2}$ Enfermeira. Doutora em enfermagem. Docente da Universidade Federal do Pará (UFPA).

${ }^{3}$ Enfermeira. Doutora em enfermagem. Docente da UFPA. E-mail: lucia.takase@pq.cnpq.br 


\section{INTRODUÇÃO}

Nas últimas décadas, o Brasil tem vivenciado intenso processo de transição demográfica, com população de características jovens passando para mais envelhecidas ${ }^{(1,2)}$. 0 rápido crescimento desse segmento da população exige revisão de políticas de saúde, que devem se basear na promoção do envelhecimento ativo e saudável, na prevenção de agravos ao longo de todo o ciclo da vida e na atenção às necessidades específicas dessa população(3).

É nessa instância que se insere o enfermeiro, que assume a figura do profissional em maior contato com o usuário do serviço de saúde, além de ser o principal responsável pelo desenvolvimento de estratégias de educação em saúde para os idosos e respectivas famílias, como, por exemplo, a criação de grupos educativos em âmbito da atenção primária ${ }^{(4.5)}$.

Nesse contexto, as tecnologias cuidativo-educacionais em saúde (TCESs) são ferramentas importantes para desenvolver o trabalho educativo e o processo de cuidar. Na área da saúde, a temática da tecnologia assume papel importante no cotidiano profissional, pois além de máquinas e equipamentos, estão à disposição dos profissionais e usuários, os mais diversos tipos de tecnologias em saúde, principalmente as leves e levesduras $^{(6)}$. As TCESs integram o grupo das tecnologias leves, denominadas tecnologia de relações, como acolhimento, vínculo, autonomização, responsabilização e gestão como forma de governar processos de trabalho(6,7).

A proposta de desenvolver uma TCES para usuários idosos partiu do interesse por aperfeiçoar o seu atendimento. Uma das condições a serem superadas no tocante a essa população é assegurar-lhe acesso aos serviços com práticas transformadoras, adotando tecnologias de cuidado da vida e saúde, que contemplem os modos de enfrentamento das múltiplas mudanças no processo de envelhecimento. Tal tecnologia leva-nos a enfatizar a necessidade de efetiva assistência básica que privilegie principalmente o caráter educativo na comunidade voltado para o bem-estar e para maior qualidade de vida de idosos vivendo em familia e comunidade ${ }^{(78)}$.

Considerando-se ser recente a inclusão da atenção à população idosa pelo SUS, a complexidade de efetivar essa atenção às múltiplas especificidades de contextos culturais e sociogeográficos demonstra ser quase impossivel prestar um cuidado de qualidade, como: promover o envelhecer ativo(9) $\mathrm{e}$ saudável; compensar incapacidades e limitações comuns da velhice; facilitar o processo de cuidar da vida e saúde do idoso e sua respectiva família cuidadora ou potencial cuidadora(10). Assim, definiu-se a seguinte questão de pesquisa: Como desenvolver uma tecnologia cuidativo-educacional para o bemviver e qualidade de vida possivel de pessoas idosas em seu curso de envelhecimento, vivendo em sua comunidade especifica? E os objetivos: realizar avaliação diagnóstica de condições de vida e saúde dos idosos convivendo em família e comunidade, usuários de uma Unidade Básica de Saúde - UBS e, testar o desenvolvimento de uma tecnologia cuidativo-educacional aos mesmos idosos, considerando o atendimento das necessidades detectadas na avaliação diagnóstica.

\section{METODOLOGIA}

Para respondera questão de pesquisa, optou-se pelo método misto, tipo sequenciado: na primeira instância, procedeu-se à avaliação diagnóstica de condições de vida e saúde dos idosos (1o objetivo), e, em seguida, ao teste do desenvolvimento de tecnologia cuidativo-educacional ( 2 ○ objetivo).

A pesquisa foi realizada na Unidade Básica Saúde do Guamá, em Belém-PA, escolhida por atender uma região de periferia, populosa e empobrecida, no primeiro semestre de 2013. Participaram 30 idosos, selecionados intencionalmente, que aceitaram participar do estudo e assinaram o Termo de Consentimento Livre e Esclarecido.

A avaliação diagnóstica dos idosos foi realizada por aplicação da Caderneta de Saúde da Pessoa Idosa (MS) e do APGAR de Familia de Smilkstein. A Caderneta criada pelo Ministério da Saúde (MS), em 2007, é ferramenta de avaliação multidimensional gerontogeriátrica que visa identificar situações de risco potenciais para a saúde da pessoa, tendo como função primordial propiciar um levantamento periódico das condições de vida e saúde do idoso que possam interferir no seu bem-estar(11). Já o APGAR de Família de Smilkstein, traduzido e validado para o Brasil, avalia a dinâmica de família no desenvolvimento e na sustentação das relações familiares, representando as dimensões: adaptação; companheirismo; desenvolvimento; afetividade; capacidade resolutiva, propostas do instrumento APGAR, cujo acrônimo vem de: Adaptation, Partnership, Growth, Affecttion, Resolve ${ }^{(12,13)}$.

Essa avaliação diagnóstica dos usuários idosos da UBS serviu de base para a concepção do planejamento estratégico educacional de TCES, aplicado a idosos selecionados por conveniência, participantes da amostra inicial.

Para testar a TCES, adotou-se o chamado grupo de convergência do método da Pesquisa Convergente-Assistencial (PCA) na modalidade de trabalho em grupo ${ }^{(14)}$. A PCA é um tipo de pesquisa ação, cujos sujeitos são os atores diretos do estudo, envolvidos na orientação para resolver ou minimizar problemas da prática, ou para realizar mudanças e/ou introduzir inovações na prática de cuidados da vida e saúde, no contexto em que ocorre a investigação. Dentre os 30 idosos da amostra inicial, o único critério de inclusão foi que assumissem o compromisso de comparecer aos sete encontros semanais que se alongariam por dois meses, formando-se assim um grupo de 13 idosos (12 mulheres e um homem)

Os encontros grupais, o primeiro e o último, tiveram objetivos específicos: o primeiro para acolhimento, apresentação da avaliação diagnóstica e discussão da programação da TCES

48 | Enferm. Foco 2016; 7 (2): 47-51 
e, o último para sintese e avaliação da aprendizagem. Do 2 으 ao 6으, os encontros foram pensados segundo a perspectiva dos participantes, coordenados pela pesquisadora enfermeira que se guiou pelo referencial teórico da enfermagem de autocuidado ${ }^{(5,10,15)}$

Do aspecto de cuidados éticos, foram respeitados os preceitos de pesquisa com seres humanos segundo diretrizes da Resolução n 466/12 do Conselho Nacional de Saúde, tendo o projeto sido submetido e aprovado pelo CEP do ICS/UFPA e protocolado sob nº $027 / 2012$.

\section{RESULTADOS}

A avaliação diagnóstica dos 30 idosos usuários da UBS resultou no seguinte perfil: 29 mulheres e um homem; idade de igual proporção de faixas etárias de 60-69 e 70-79; predominando 15 idosas casadas. A escolaridade da maioria (23) atingia de quatro a oito anos de estudos. Quanto à ocupação, predomínio de 21 idosas aposentadas, demonstra reflexo da escolaridade maior entre as mulheres, favorecendo o emprego ao longo da vida e usufruto atual de aposentadoria. Quanto aos hábitos de vida, apenas três fumam atualmente, enquanto oito dizem beber com frequência; a maioria (22) pratica atividade física. Constatou-se também que a maioria não apresenta restrição física. Quase todos os idosos moram em arranjos multigeracionais, embora 18 deles passem a maior parte do dia sozinhos, com a ressalva em 22 dos casos, de que teriam, quando necessário, cuidadoras familiares. Quanto à avaliação da dinâmica familiar, 20 dos idosos classificaram sua família como sendo de alta funcionalidade, contra seis, de moderada funcionalidade, pressupondo-se que a maioria está satisfeita com o relacionamento e atendimento da família a suas demandas cotidianas de vida doméstica e social. Quanto à morbidade por Doenças Crônicas não Transmissiveis (DCNT), encontrou-se alto índice de 14 idosos sofrendo de Hipertensão Arterial Sistêmica (HAS).

Essa avaliação diagnóstica serviu de base para a concepção do planejamento estratégico educacional de TCES, desenvolvida entre os 13 idosos selecionados por conveniência, da amostra inicial. Dos dados emergidos e reflexões tidas durante a aplicação da TCES, levando-se em conta as competências e práticas de autocuidado(10,11,15), referencial de enfermagem adotado, seguem duas categorias principais.

\section{a)Autocuidado em desvios de saúde: enfrentando a cronicidade}

Emergiram questões como: a nutrição interferindo no controle das afecções crônicas; o temor às demências; os riscos de fragilização como hospitalização e quedas, incluindo efeitos adversos de medicação; o receio de perda da libido; o desconhecimento das causas de aumento do HIV/AIDS em idosos. Assim, entre os receios, destacou-se a questão da perda da libido em decorrência de certas medicações usadas, o que exigiu discussão sobre melhores orientações profissionais: [...] depois que fui diagnosticado de diabetes e comecei a tomar a medicação, afetou meu desempenho sexual. Tive que discutir isso com o medico (Bem-me-quer); Aumento de AIDS na velhice? Isso a gente não fala, não sabemos... (Violeta $e$ Perpétua).

Já o temor ao esquecimento, atribuindo o mal à doença de Alzheimer, também apareceu nas discussões que mereceram reorientações: O telefone tocou e eu estava fazendo doce no fogão; fui atender o telefone e esqueci o fogo aceso, fiquei preocupada [...] será que já tenho aquela doença? (Violeta);[...] faz um mês que venho percebendo problema de memória. A senhora acha que estou com Alzheimer? Venho apresentando dificuldade de lembrar coisas, como onde guardei a chave, o dinheiro; estou esquecendo de dar recados... mas sou boa de número [...] (Açucena).

\section{b) Requisito de autocuidado desenvolvimental}

A tônica da discussão girou em torno de preconceitos: contra idoso, contra sexualidade na velhice, contra direito à cidadania. Ao discutir preconceitos, observou-se conhecimento e interesse dos idosos, embora ainda prisioneiros de mitos e tabus, inclusive de autopreconceito presente.

Muitas vezes, os idosos sentem vergonha e consideram que sexo é algo somente para jovens; embora concordem que o envelhecimento não os exime de usufruir a sexualidade, conforme as falas: Acho que se eu ficasse viúva, eu podia até querer arrumar um namorado (Violeta); [...] ficar com meu velho abraçadinha é tão gostoso (Hortência). A discussão dessa temática teve grande repercussão entre as idosas, como se observa na fala: [...] quando casei não sabia nada sobre sexo [...] (Orquidea); [... ninguém conversava sobre sexo na minha casa; minha criação foi de - beijar engravida (Cambraia).

Discutir com o grupo sua visão em relação à sexualidade foi importante para perceber o quanto necessitavam de ações de educação que os auxiliassem no desenvolvimento de competências para o empoderamento relacionado à sexualidade, como também buscar orientações específicas em face das intercorrências próprias do envelhecimento, como revelam suas falas: [...] sempre peço para a assistente social, gel lubrificante que é distribuido na unidade pois ajuda na relação sexual (Violeta e Perpétua).

A avaliação obtida após a experiência, de melhora na dinâmica familiar, pressupõe possível influência da vivência dos idosos por dois meses em prática educativa do repensar reflexivo de seu próprio envelhecimento. Tal avaliação, da maioria ${ }^{(12)}$, de atribuir a dinâmica de sua familia com boa funcionalidade, em comparação à aplicação anterior, com resposta de nove, denota efeitos que extrapolaram o convívio grupal, o da convivência familiar, com uma visão mais abrangente de crescimento nas relações humanas de modo 
mais horizontalizado e comprometido. Corrobora-se isso com dados subjetivos resultantes de manifestação dos participantes no último encontro, cujo posicionamento positivo foi assim revelado: Depois desses nossos encontros minha vida mudou, tenho outro jeito de pensar em relação a como envelhecer com qualidade [...] (Cambraia); No grupo passamos a entendermelhor sobre os direitos dos idosos [...] de como cuidar-se melhor [...] a gente teve a oportunidade para falar o que sabemos e tirar as nossas dúvidas [...] a enfermeira trabalhou com brincadeiras [...] facilitou nosso aprendizado [...] (Violeta).

\section{DISCUSSÃO}

A avaliação diagnóstica realizada dos idosos usuários da UBS neste estudo resultou num perfil semelhante a de outros estudos $^{(8,16)}$ desenvolvidos em contextos sociogeográficos similares de periferia empobrecida de cidades paraenses. Ressalta-se nesse perfil: a predominância de mulheres, um fato já observado de serem elas usuárias ativas de UBS. As condições de vida e saúde, avaliadas pela Caderneta do Idoso(11), demostraram que idosos moram em arranjos multigeracionais e têm, quando necessário, familiares cuidadores. A maioria sofre de alguma DCNT, com alto índice de idosos com HAS.

Com base nesse quadro diagnóstico, se desenvolveu a atividade educacional de TCES junto aos idosos selecionados, que cumpriram as sessões educacionais. Assim, ao longo dessas sessões, observou-se prenúncio de empoderamento para o autocuidado, em sinais emitidos nas falas: a tomada de consciência quanto às questões da velhice, mudanças na prática de cuidado relativo ao enfrentamento das intercorrências de saúde no transcurso do envelhecimento ${ }^{(5,17)}$.

\section{a) Autocuidado em desvios de saúde: enfrentando a cronicidade}

O processo educativo sobre prevenção e/ou controle da HAS e Diabetes Mellitus (DM) ocorreu de maneira contínua e dinâmica, discutindo-se os fatores de risco: seu reconhecimento e modos de enfrentamento.

Depoimentos sobre perda da memoria ensejaram discussão sobre estimulação da memória, como prática necessária do cotidiano, pois é a alteração cognitiva que mais preocupa os idosos(11). Alterações esperadas no envelhecimento incluem diminuição na memória operacional e na memória episódica ${ }^{(18)}$. Nesse momento, fica clara a importância e a presença da (o) enfermeira (o) capacitada (o) especificamente em gerontogeriatria ${ }^{(10)}$ para estimular as competências para o autocuidado dos idosos, por meio da sistemática de apoio/ educação preconizada por Orem ${ }^{(15)}$.

Ainda na prevenção, em temas de desvio de saúde, discutiuse sobreas Infecções Sexuamente Transmissiveis(IST), incluindo o HIV/AIDS em idosos, cuja epidemiologia denuncia incidência crescente de casos positivos ${ }^{(19)}$. De modo geral, as relações amorosas das idosas representam um déficit de competência ao autocuidado na prática da sexualidade saudável e segura. As reflexões com as idosas giraram em torno de esclarecimentos sobre doenças sexualmente transmissiveis, incluindo o HIV/ AIDS e os comportamentos de vida sexual segura, denotando que essas idosas passaram a considerar que, para adquirir tal competência, teriam de enfrentar e superar a resistência do parceiro, empoderando-se para discutir com o mesmo de maneira horizontal(20-22).

A questão da sexualidade na terceira idade abrange também preconceitos entre os próprios profissionais de saúde que não solicitam a sorologia para o HIV prontamente e nem indagam os idosos sobre a vida sexual. Enquanto isso, a desinformação, conforme alegada pelos idosos, perpetua entre eles como se fossem imunes ao vírus ${ }^{(23,24)}$.

\section{b) Requisito de autocuidado desenvolvimental: o idoso como protagonista de seu próprio envelhecimento}

Ao trabalhar o autopreconceito, percebiam-se, por exemplo, quanto à própria sexualidade. A velhice pode ser saudável e prazerosa com cuidados e hábitos desenvolvidos durante toda a vida, como competências, habilidades e um estilo de vida.

O fato de não ser jovem não implica necessariamente abdicar dos prazeres da vida, incluindo a satisfação sexual(21).

A sexualidade foi discutida com os idosos e estimulada dentro de uma prática saudável e sem estigmas, o que deve representar mais um fator a contribuir para uma vida autônoma, plena e prazerosa ${ }^{(25)}$. A sociedade em geral, ainda nos dias de hoje, desconsidera que as mudanças que ocorrem no processo do envelhecer não impedem que os idosos vivenciem sua sexualidade como parte de um processo natural ${ }^{(22)}$.

O direito à cidadania foi a questão que buscou trabalhar a competência do idoso em relação a sua própria velhice. Constata-se que idosos da amostra exercem outras atividades de lazer, sociais, culturais e espirituais na comunidade e também na familia, o que os mantém ativos e com sua autonomia preservada, gozando de respeito e estima na comunidade ${ }^{(9)}$.

Em face da satisfação pessoal de cada idoso participante com os beneficios obtidos em termos de novas aprendizagens, oportunização de debate aberto sobre sexualidade (tema ainda proibitivo na relação cotidiana atual), despertar da necessidade de empoderamento das idosas para enfrentar a desigualdade de gênero em questões de prática sexual segura, saudável e prazerosa, atestam-se ganhos positivos.

Considerando tais resultados, embora provisórios, e ser essa tecnologia leve e leve-dura de cuidado fundada no trabalho de saúde em ato de cuidar/ensinar, sua replicação é possivel, porém tomará sempre matizes próprios do contexto geográfico e temporal e da situação de aplicação que sempre será peculiar.

Da avaliação geral, infere-se que a (o) enfermeira (o) pode atuar no fortalecimento de competências para o autocuidado do idoso, rumo ao protagonismo do próprio envelhecimento 
com qualidade.

A limitação do estudo se observa em razão de ter sido ainda uma testagem inicial da TCES, embora apresentando sinais positivos de resultados benéficos tanto aos idosos quanto para enfermeiras (os). Por se tratar de experiência inicial e limitada, essa TCES carece de sucessivas replicações em diferentes contextos, sempre visando apoiar ações cuidativo-educacionais da (o) enfermeira (o) no atendimento do usuário idoso com vistas a alcançar o envelhecimento ativo e saudável.

\section{CONCLUSÃO}

O estudo, embora limitado ainda, de testagem inicial, apresentou resultados benéficos aos idosos que se submeteram à experiência e também à enfermagem, pela possibilidade de empreender ações cuidativo-educacionais inovadas a favor do autocuidado no envelhecimento.

O estudo revelou perspectivas para o enfermeiro ser facilitador no desenvolvimento de competências para o autocuidado e estimulador dos idosos como protagonistas do próprio envelhecimento, instrumentalizado por diretrizes da tecnologia leve de atos de relação no cuidado.

\section{AGRADECIMENTOS}

Ao $\mathrm{CNPq}$ pelo apoio financeiro - Edital Universal, proc. 480422/2013-3. Aos idosos usuários da UBS do Guamá pela disponibilidade em participar da pesquisa. Àeducadora Raphaela Monteiro Goes, pela disponibilidade em ser treinada e participar no Grupo de convergência atuando como observadora, gravando e anotando todo o evento grupal.

\section{REFERÊNCIAS}

1. Veras R. Prevenção de doenças em idosos: os equívocos dos atuais modelos. Cad Saúde Pública. 2012;28(10):1834-40.

2. IBGE - Instituto Brasileiro de Geografia e Estatística. Censo Demográfico (IBGE, censo sinopse 2010). Rio de Janeiro: IBGE, 2010 [citado em 20 Jan 2014]. Disponivel em: www.ibge.gov.br

3. Mendes ACG, Sá DA, Miranda GMD, Lyra TM, Tavares RAW. Assistência pública de saúde no contexto da transição demográfica brasileira: exigências atuais e futuras. Cad Saúde Pública. 2012:28(5):955-64.

4. Silveira RE, Mendonça FTNF, Santos AS, Filipe EMV. Estratégias de educação em saúde para idosos: experiências e desafios. Cultura de los Cuidados [Online]. 2015;19(42):154-63. doi:10.14198/cuid.2015.42.14

5.Valcarenghi RV, Lourenço LFL, Siewert JS, Alvarez AM. Produção cientifica de enfermagem sobre promoção de saúde condição crônica e envelhecimento. Rev Bras Enferm. 2015;68(4):705-12.

6. Merhy EE. Saúde: cartografia do trabalho vivo em ato. São Paulo (SP): Hucitec: 2002.

7.Gonçalves, LHT, Schier, J. "Grupo Aqui e Agora" - Uma tecnologia leve de ação sócio-educativa de enfermagem. Texto Contexto Enferm. 2005:14(2):271-9.

8. Polaro SHI, Gonçalves LHT, Alvarez AM. Enfermeiras desafiando a violência no âmbito de atuação da Estratégia de Saúde da Familia. Texto Contexto Enferm. 2013:22(4):935-42.

9. WHO - World Health Organization. Envelhecimento ativo: uma politica de saúde. Brasilia: Organização Pan-Americana de Saúde; 2005.

10. Gonçalves LHT, Alvarez AM, Santos SMA. A enfermagem gerontogeriátrica e sua especificidade. In: Gonçalves LHT, Tourinho FSV. Enfermagem no cuidado do idoso hospitalizado. Barueri: Manole; 2012. p. 3-25.

11.Brasil. Ministério da Saúde. Secretaria de Atenção à Saúde. Caderneta de Saúde da Pessoa Idosa: Manual de preenchimento. Brasilia: Ministério da Saúde; 2008 .

12. Duarte YAO. Familia: rede de suporte ou fator estressor: a ótica dos idosos e cuidadores familiares [tese]. São Paulo (SP): Escola de Enfermagem, Universidade de São Paulo (USP); 2001.

13. Brasil. Ministério da Saúde. Secretaria de Atenção à Saúde. Envelhecimento e saúde da pessoa idosa. Brasilia: Ministério da Saúde; 2007. (Caderno de Atenção Básica n. 19).
14. Trentini M, Gonçalves LHT. Pequenos grupos de convergência: um método no desenvolvimento de tecnologias em enfermagem. Texto Contexto Enferm. 2000:9(1):63-78.

15. McEwen, M., Wills, E. M. Bases teóricas de enfermagem. $2^{a}$ ed. Porto Alegre: Artmed; 2009

16. Gonçalves LHT, Polaro SHI, Carvalho JN, Goes TM, Medeiros HP Souza FJD. Condições de vida e saúde de idosos amazônidas: realidade de comunidades periféricas de cidades paraenses. Rev Enferm UFPE [online] 2015; 9(1):39-46.

17. Janini JP, Bessler D, Vargas AB. Educação em saúde e promoção da saúde: impacto na qualidade de vida do idoso. Saúde Debate. 2015 39(105):480-90.

18. Carvalho FCR, Neri AL, Yassuda MS. Treino de memória episódica com ênfase em categorização para idosos sem demência e depressão. Psicol Reflex Crit. 2010; 23(2):317-23.

19. Brasil. Ministério da Saúde. Coordenação Nacional DST/Aids - Vigilância Epidemiológica. Boletim Epidemiológico de AIDS. 2010 Jan/Jun; Ano III(1).

20. Miranda AS, Gonçalves LHT. Autocuidado de mulheres residentes amazônidas na prevenção e controle do papiloma virus (HPV) - participação da (o) enfermeira (o). Enferm. Foco2016;7(1):8-12.

21. Vieira KFL. Sexualidade e qualidade de vida do idoso: desafios contemporâneos e repercussões psicossociais [tese]. Universidade Federal da Paraiba, João Pessoa (PB); 2012

22. Castro SFF, Nascimento BG, Soares SD, Barros Junior FO, Sousa CMM, Lago EC. Sexualidade na terceira idade - a percepção do enfermeiro da estratégia saúde da familia. RevEnfermUFPE [online]. 2013[citado em 14 Out 2013];7(10):5907-14. Disponivel em: http://www.revista.ufpe.br/ revistaenfermagem/index.php/revista/article/view/4606.

23. Santos AFM: Assis M. Vulnerabilidade das idosas ao HIV/AIDS: despertar das políticas públicas e profissionais de saúde no contexto da atenção integral: revisão de literatura. RevBrasGeriatrGerontol [Internet]. 2011 citado em 20 Jan 2014];14(1):147-57. Disponivel em: http://revista.unati.uerj. $\mathrm{br} / \mathrm{pdf} / \mathrm{rbgg} / \mathrm{vl}$ nl/v14nlal5.pdf

24. Castro SFF, Costa AA, Carvalho LA, Barros Júnior FO. Prevenção da AIDS em idosos: visão e prática do enfermeiro. Ciênc Saúde (Porto Alegre). 2014:7(3):131-40.

25. Socci V. Vida afetiva e amorosa do adulto idoso. In: Witer C, Buriti MA Org. Envelhecimento e contingências da vida. Campinas (SP): Alínea; 2011 Cap. 2p. 41-58. (Coleção Velhice e Sociedade). 